\title{
Research on the Development Path of Southwest National Sports From the Perspective of "Cultural Confidence"
}

\author{
Liqing Zhang ${ }^{1, *}$ \\ ${ }^{1}$ College of Physical Education and Health Sciences, Yangtze Normal University, Chongqing, China \\ ${ }^{*}$ Corresponding author.
}

\begin{abstract}
Improving national cultural confidence is the fundamental appeal for national unity. The research mainly adopted document literature, field investigation, logic analysis and other research methods. It took the national traditional sports culture as the research object, examined the development difficulties of the national traditional sports culture in the southwestern region from the perspective of cultural self-confidence, and discovered the demise of traditional ethnic sports and inheritors, the lack of value in the times, the lack of project funds, and the simple way of inheritance, etc. It proposed to increase the investment of special funds in projects and inheritors, accurately support the project inheritance problem, establish the "economic benefit + cultural value" double increase model and the traditional national sports project innovation platform exchange construction development path to provide relevant reference basis.
\end{abstract}

\section{Keywords: Southwest China, traditional national sports, inheritance and protection}

\section{INTRODUCTION}

The report of the Nineteenth National Congress of the Party profoundly stated that "culture is the soul of a country and a nation." When culture is prosperous, the country will be prosperous, and when culture is strong, the country will be strong. Without a high degree of cultural confidence and cultural prosperity, there will be no great rejuvenation of the Chinese nation". The cultural confidence of the traditional sports culture of the Chinese nation is an internal demand for the great rejuvenation of the Chinese nation and an important part of the development of sports culture in the new era. The southwestern region is a gathering place for ethnic minorities in China, with a rich variety of traditional national sports. With the development of the times, the changes in people's production and lifestyle, coupled with the impact of Western sports culture, the Chinese national sports in the southwest area have undergone earth-shaking changes. By inputting "National Traditional Sports Culture" and "National Traditional Sports Culture of Southwest Region" and "Traditional Ethnic Sports Culture of Minorities" into the CNKI (China National Knowledge Infrastructure) database and knowledge map analysis, it can be seen that at present, most studies of traditional national sports culture are limited to the perspective of protection and inheritance. Therefore, this article takes the opportunity of integrating the Belt and Road Initiative from the perspective of cultural confidence as well as the related theoretical research to try to explore the development path and theoretical basis of the cultural confidence of Chinese national traditional sports culture in Southwest China.

II. THE VALUE OF THE DEVELOPMENT OF SOUTHWEST NATIONAL SPORTS CULTURE FROM THE PERSPECTIVE OF CULTURAL CONFIDENCE

Culture is the sum of material and spiritual wealth created by human society in the course of historical development. Cultural confidence is the inner awe and respect of a country, a political party or a nation for its doctrine, ideals and values, and the positive psychological state resulting from it. Xi Jinping pointed out: "Cultural confidence is a more basic, broader and deeper self-confidence." Southwest minority areas include Sichuan, Yunnan, Tibet, Chongqing, Guizhou, and Wuling Mountain areas, inhabiting 29 ethnic minorities, with more than 36 million people, accounting for about $34 \%$ of the national minority population. Due to the unique natural environment and lifestyle, various regions have formed distinctive national traditional sports culture, and formed more than 470 national traditional sports. The traditional national sports culture is a necessary condition for the generation of cultural confidence, which fully reflects the stubborn vitality of the traditional national sports in Southwest China. In the context of the new era, the value of traditional national sports culture in Southwest 
China is mainly as follows: the first is the value of fitness and entertainment. As China's struggle against poverty is about to win, the southwest minority areas are gradually getting rid of poverty and backwardness, and people are paying more and more attention to health. Chinese national festival activities have become an important part of daily life, of which people integrate modern music rhythm to perform, such as: Tujia handwaving dance, Gelao large-scale snatching fireworks, big shuttlecock, money stick, etc. The second is the inheritance value of national culture. There are many ethnic traditional sports in Southwest China, most of which are extracted from production and life. They have the function of educating future generations, and play the role of inheriting history and culture, thus highlighting the characteristics of ethnic culture. The third is the value of moral education. The traditional national sports in southwestern China pays attention to the cultivation of team spirit, civilization and politeness, solidarity and mutual trust, and other fine traditions, which have the significance of education in the times.

\section{THE REALISTIC PREDICAMENT OF THE DEVELOPMENT OF SOUTHWEST NATIONAL TRADITIONAL SPORTS CULTURE}

\section{A. The demise of national traditional sports and inheritors}

The southwest region is rich in national traditional projects and has a solid heritage of traditional sports culture. In the period of economic transformation in the new era, the protection and inheritance of traditional national sports are facing a grim situation. Some projects with weak modern values are already dying, such as the shuttlecocks in Pengshui County of Chongqing and the vaulting horses of Manchu. For project protection and inheritance, the project inheritor is the key. At present, the inheritors have the following outstanding problems.

The project inheritors are older and not well educated Changes in modern lifestyles have made the project successors of the elders pass on to the next generation in the best period, encountering their own low cultural level, and the heirs are forced to work or work under the pressure of the economy. Two factors have caused the original inheritors to grow old one after another, or to die with the project, such as Qianjiang Xiang's martial arts.

There is a disagreement among the project inheritors. There are many national traditional sports in my country. However, many genres such as Wudang, Shaolin, Emei and Nanquan appeared in the process of formation. Due to conflicts in development philosophy and economic interests, there was a divergence of mutual recognition among the inheritors.
The degree of industrialization of traditional projects is low. The traditional sports of ethnic minorities in the southwest region have made remarkable achievements in the development of the local sports industry. For example, traditional national sports activities such as Leishan Niutou in Guizhou and Diaoyang in Xinjiang attracted a large number of tourists to visit and experience, and received good economic benefits. However, the scale of the industry is not large, and the communication needs to be strengthened.

\section{B. Insufficient value mining of traditional national projects, and ignoring essential cultural characteristics}

Whether a project can be carried forward cannot ignore its essential cultural characteristics, but the reality is not the case. In the course of the investigation, it was found that in order to attract tourists to their farmhouse for consumption, the merchants close to the scenic spot would perform in strange costumes, which greatly erased the essential cultural characteristics, such as the hand-waving dance of Tujia. However, on the other hand, the traditional sports of national sports contains rich spiritual and cultural connotations. If the excavation is insufficient, it will inevitably go to extinction. Therefore, digging deeply into the times value of traditional national sports is an effective way for sustainable development.

\section{THE ORIGIN OF THE DILEMMA OF TRADITIONAL SPORTS CULTURE DEVELOPMENT IN SOUTHWEST CHINA}

\section{A. Inadequate funding for traditional national sports culture}

The development of sports activities requires its own stubborn vitality and the support of external forces. The promotion of special funds is very important. Through interviews and investigations, it is found that traditional sports projects in many places are not supported by special funds. Only a few projects have financial support and limited support. For example, the Chongqing municipal government has given support to the development of traditional national sports projects, only 5,000 yuan in funding for the project inheritors themselves, which has little effect on the project itself. Moreover, the development of individual projects is not something that can be undertaken by an individual inheritor. It is more about the cultivation of collective projects. Therefore, project funding should be inclined to project inheritors and projects, and special funding should be appropriately increased to support them. 


\section{B. Inheritance of traditional national sports}

The inheritance of traditional national sports projects mainly has the following two aspects: the first is the issue of project inheritors; about the project protection and inheritance, the inheritor is the key, and the receiver is also the key. At present, the most prominent problem of inheritors is that the population is aging and the education level is not high, which leads to inheritance resistance, and the inheritors are forced by economic pressure, and focus more on personal family economic development The second is the project "factions" are diversified. During the investigation, it was found that there are a large number of projects of the same kind, there are diversified "factions", and there is a debate about the existence of "authentic" factions.

\section{The inheritance method is old and simple, and the modern scientific and technological means are insufficient}

$5 \mathrm{G}$ technology, big data, and cloud technology have brought opportunities for the development of traditional national sports. However, due to the limited cultural level of the inheritors, the traditional "oral teaching" model has been unable to meet the development of the project. Through statistical investigation, it is found that the traditional ethnic sports on the verge of extinction all have a characteristic, that is, the value of the times is insufficient, and lifestyle changes are external factors, but internal factors are more worthy of mining. The Chinese national culture is broad and profound, and its connotation analysis is the only way for sustainable development. In the same way, the sustainable development of the national traditional sports project culture has appeared a situation where modern value mining is insufficient and unsustainable.

\section{THE DEVELOPMENT PATH OF NATIONAL TRADITIONAL SPORTS CULTURE FROM THE PERSPECTIVE OF CULTURAL CONFIDENCE}

\section{A. Increasing the investment of special funds in projects and inheritors}

National traditional sports culture is an important part of traditional culture and the source of sustainable development of cultural diversity. From the perspective of cultural confidence, it is an indispensable and important part of the strategy of strengthening the country. Therefore, the state should increase the investment of special funds, raise special funds through multiple channels, ensure that the special funds are used exclusively, and strengthen the supervision of project funds.

\section{B. Accurate support project inheritance issues}

The dilemma of the development of national traditional sports culture is concentrated in two aspects.
First, the objective problems of project inheritors are mainly manifested as: the age of the inheritors is not high in education; the inheritance mode is simple and the application of modern technology is lacking. Second, the problem of a sharp decline in the number of inherited persons is mainly manifested in: lifestyle changes. It means that young people are forced by economic pressure to leave the village or their hometown to work. In response to the above-mentioned problems, the development of traditional ethnic sports should be accurately supported. For the aging of the inheritors, the government should solve their life dilemma, give living allowances or poverty assistance, etc., so that the inheritors can have no worry about their food and clothing, exert their subjective initiative, and concentrate on project inheritance. It also should train the inheritors of modern technology to make them proficient in the use of modern science and technology. For complex modern technologies such as: video editing, post-production, dynamic image processing, etc., professional personnel should be equipped to provide precise assistance. In the context of the Western Development Strategy, ecological development has become an important part of the productivity of the new era. In view of the difficulties faced by the inherited persons are mainly because of the pressure of the living economy and the low professional skills, working out or working at home can only solve the basic living security. China's entry into poverty alleviation in 2020 will bring historical development opportunities to regions with backward economic development, and ecological development will become the mainstream of green development. The survey found that the development of the ecotourism industry and technical vocational education can alleviate the economic situation in the region, and young people can live in peace, and the prerequisites for participating in traditional national sports are guaranteed. Coupled with the investment of special funds in the project, it can guide the inherited person to participate in the national traditional sports project, and enhance the identification of national cultural confidence.

\section{Starting the "economic benefit + cultural value" double increase model}

When developing the cultural value of traditional national sports, it is an effective way to achieve sustainable development by taking into account its economic effects. The survey found that all welldeveloped national traditional sports have a common feature, and the value of the spirit of the times is significant. For example, Xiang's martial arts contain the idea of "not bullying the weak, protecting the home and protecting the country", and the hand-waving dance contains the spiritual connotation of "striving for selfimprovement, cultural identity, national selfconfidence". This is precisely coupled with the 
"cultural self-confidence" among the four selfconfidences of the strategy of strengthening the country. And mining the spiritual connotation of many projects is very boring to ordinary people. Therefore, it should be consolidated with the "ritual" form of traditional national sports. Using the ritual form before the Taekwondo competition, it can learn the connotation spirit of traditional national sports.

\section{Exchange and construction of innovative platforms for traditional national sports}

For the development of traditional national sports projects, it is necessary to make full use of modern science and technology to establish a communication platform for traditional national sports, and to protect traditional national sports through modern technologies such as cloud space, WeChat public platform, and virtual reality (VR) technology. In addition, the project can be used to promote, protect and inherit the project through digital platforms, and establish dynamic images such as pictures + text + music to show the traditional national sports culture. For multi-genre national traditional sports projects, it is necessary to establish a forum to discuss the area, to discuss the project development concept, communication methods, modern value characteristics and other topics. Through discussion in the forum, it can select outstanding national traditional sports items with high modern value, strong development concept, and easy dissemination, and develop national traditional sports through industrialized management. For example, the martial arts project "Wulin Feng" has attracted the attention of martial arts enthusiasts. The Leishan bullfight in Guizhou and the hand-waving dance in Chongqing have formed a sustainable development model.

\section{CONCLUSION}

This paper studies the development of Southwestern national sports projects from the perspective of cultural confidence. Through research, it is found that the value of traditional national sports culture in Southwest China has the following three aspects: first, the value of fitness and entertainment; second, the value of inheritance of national culture; third, the value of "quality" education. The practical development dilemma is mainly realized as follows: first, the demise of traditional ethnic projects and inheritors; second, the lack of modern value mining of projects, ignoring the essential cultural characteristics. The sources of development dilemma are mainly in the following aspects: first, insufficient special project funds; second, the problem of inheritance of ethnic projects; third, the old and single inheritance method, and insufficient modern scientific and technological means. Therefore, to realize the development of national traditional sports culture is to adhere to the premise of cultural confidence, scientifically examine the value of traditional sports projects in Southwest China, and use project development as a carrier to develop national traditional sports culture in a sustainable manner. The following cultural development paths in the southwestern region are proposed: the first is to increase the investment of special funds in projects and inheritors; the second is to accurately support project inheritance issues; the third is to open the "economic benefit + cultural value" double increase model; the forth is the exchange construction of innovative platforms for national traditional sports.

\section{References}

[1] Xi Jinping, Decisively Win a Well-off Society in an All-roun Way, and Capture the Great Victory of Socialism with Chinese Characteristics in the New Era - Report at the 19th National Congress of the Communist Party [M]. Beijing: People's Publishing House, 2017. (in Chinese)

[2] Tuo Peixing, The Value, Dilemma and Dispelling of Crosscultural Communication of National Traditional Sports under the "All Along the Way" Strategy [J]. Journal of Nanjing Institute of Physical Education (Social Sciences), 2017, 31(01). (in Chinese)

[3] Li Ying, Yang Fenglei, Value and Strategy of Developing Chinese Traditional Sports and Enhancing Cultural Confidence [J]. Sports Culture Guide, 2020 (02): 1-5+23. (in Chinese)

[4] Liu Erxia, An Analysis of the Multi-value of Ethnic Traditional Sports from the Perspective of Cultural Confidence Comment on "Introduction to Traditional National Sports Culture" [J]. China Forest Products Industry, 2019,56(10): 67 (in Chinese)

[5] Liu Guoli, Liu Xiaoqian, Research on the Status Quo and Development Path of National Traditional Sports - Comment on "Cultural Review of the Development of National Traditional Sports" [J]. Journal of The Chinese Society of Education, 2019 (08): 132. (in Chinese)

[6] Wang Yongjian, Wu Jianping, Study on the Dissemination and Cultural Exchange of Traditional National Sports in the New Era [J]. Guizhou Ethnic Studies, 2019, 40(05): 145-148. (in Chinese)

[7] Xue Hao, The Formation Mechanism and the Development of Chinese Traditional Sports Culture [J]. Sports Culture Guide, 2019 (05): 41-46+52. (in Chinese)

[8] Dong Suyun, Modern Development of the Characteristics and Functions of Traditional Sports of Ethnic Groups in Southwest [J]. Guizhou Ethnic Studies, 2012, 33(03): 157-160. (in Chinese)

[9] Yong Guijun, Multiple Thinking on the Protection and Innovation of Southwest Minority Traditional Sports [J] Heilongjiang National Series, 2010(03): 164-167. (in Chinese)

[10] Zhong Haiming, Analysis on Cultural Anthropology of Traditional Southwest Minority Sports [J]. Heilongjiang National Series, 2008(03): 146-149. (in Chinese)

[11] Yuan Ying, Research on Traditional Sports and Development Modes in Northwestern Nationalities [J]. Heilongjiang National Series, 2008(01): 156-160. (in Chinese) 